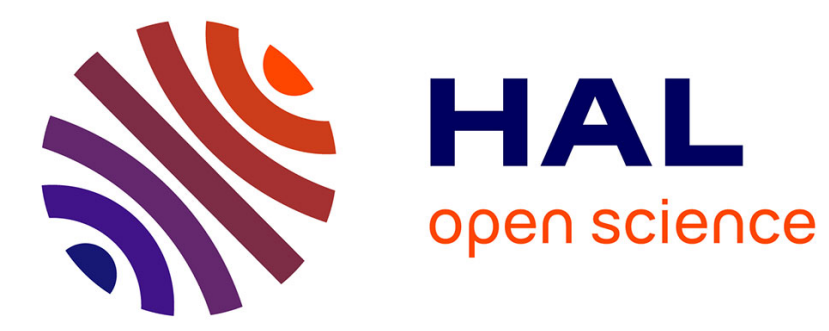

\title{
Mapping the electric field vector of guided ionization waves at atmospheric pressure \\ Sylvain Iséni
}

\section{To cite this version:}

Sylvain Iséni. Mapping the electric field vector of guided ionization waves at atmospheric pressure. Plasma Research Express, 2020, 2 (2), pp.025014. 10.1088/2516-1067/ab9b69 . hal-02878527

\section{HAL Id: hal-02878527 \\ https://hal.science/hal-02878527}

Submitted on 23 Jun 2020

HAL is a multi-disciplinary open access archive for the deposit and dissemination of scientific research documents, whether they are published or not. The documents may come from teaching and research institutions in France or abroad, or from public or private research centers.
L'archive ouverte pluridisciplinaire HAL, est destinée au dépôt et à la diffusion de documents scientifiques de niveau recherche, publiés ou non, émanant des établissements d'enseignement et de recherche français ou étrangers, des laboratoires publics ou privés.

\section{(ㅇ)(1) $\$$}

Distributed under a Creative Commons Attribution - NonCommercial - NoDerivatives| 4.0 


\title{
Mapping the electric field vector of guided ionization waves at atmospheric pressure
}

\author{
Iseni $\mathbf{S}$. \\ GREMI-(Groupe de Recherches sur l'Énergétique des Milieux Ionisés) - \\ UMR 7344 CNRS/Université d'Orléans, France. \\ E-mail: sylvain.iseni@univ-orleans.fr
}

\begin{abstract}
In this study, the dynamic of guided ionization wave (IW) generated by an atmospheric pressure plasma jet (APPJ) device operating in helium is experimentally investigated. The present work focuses on the properties of the intense electric field (EF) driving the IW. Taking advantages of APPJs to produce guided and reproducible IWs, the induced EF vector is characterized spatially and temporally along the direction of propagation. With this approach, EF vector mapping of guided IWs have been measured and documented for the first time. In the first part, the propagation within a glass tube of the first IW is investigated. Under the present conditions, a second guided IW is observed and propagates, leading to the formation of a guided streamer. The EF due to transient charge deposited on the wall surface is observed, particularly at the end of the tube. In the second part, one reports on the EF vector mapping under a dielectric substrate in contact with guided IWs. EF strength up to $55 \mathrm{kV} / \mathrm{cm}$ has been measured and corroborates prior results from predictive numerical simulations. Intriguing configurations of the EF lines will be of significant interest to validate theoretical models in order to refine the non-equilibrium plasma chemistry kinetics. Furthermore, this preliminary work provides important insights into various applications involving IW driven discharges such as liquid activation, environmental treatments, plasma medicine, active flow control and plasma agriculture.

This is the Accepted Manuscript version (post-print) of an article accepted for publication in PlaSma RESEARCH EXPRESS. IOP Publishing Ltd is not responsible for any errors or omissions in this version of the manuscript or any version derived from it.

The Version of Record is available online at doi:10.1088/2516-1067/ab9b69.
\end{abstract}




\section{Introduction}

Room temperature atmospheric pressure plasma sources have been massively developed over the past decade aiming at various applications in the fields of biology and medicine [1, 2], environmental science and liquid activation [3, 4], surface activation and material processing $[5,6]$ and active flow control [7]. The uniqueness of non-thermal plasma combining different forms of energy - electric, ionization, chemical, radiant and thermal - yields a rich reactive chemistry [8]. The production of reactive species depends strongly on the type of plasma source [9]. Among those, cold atmospheric pressure plasma jet (APPJ) offers the advantages of a cheap construction, a simple design and flexibility to integrate into industrial processes. A large amount of electrical configurations and geometries have been reported in the literature [10]. Up-to-date additional technological aspects have been summarized in [11].

In most APPJ devices, the plasma formation is due to the propagation of guided ionization waves (IW) also named in the literature as pulsed atmospheric pressure plasma streams (PAPS) [12] or more commonly guided streamer [13]. Operating at atmospheric pressure, atomic gases such as helium, argon or neon are used mainly for their chemical neutrality and ionization properties. The morphology of guided IW depends on the gas and admixtures (typically $\mathrm{N}_{2}$ or $\mathrm{O}_{2}$ ), producing a rather diffuse or filamentary discharge [14]. The mechanism of guided IW has been extensively reviewed in [15] from a theoretical and an experimental point of view. Briefly, with the presence of high external electric field (EF), atoms and molecules of the gas mixture are ionized by electron impacts leading to the formation of a space charge. The density of volumetric charges contributes to the enhancement of the local EF in the front exceeding the external applied EF and allowing for the propagation of the IW. Guided IW have the additional features of a predictable and reproducible direction propagation, of the bright ionization front containing highly energetic electrons and photons being favorable for the creation of a darker - partially ionized channel. The intense light emission of the guided IW front was observed first using high-speed photographs, where the term "plasma bullet" is suggested as a phenomenological description [16]. Later, the evidence of the front is reported with the first measurement of EF strength up to $26 \mathrm{kV} / \mathrm{cm}$ in guided IW in helium, by means of Stark polarization emission spectroscopy [17] and confirms prior results of numerical simulations [18]. Recent studies involving a similar plasma source have been carried out to characterize the EF resulting from the space charge ahead of the IW and before the first light coming from the ionization front [19]. In [20], the same group proposed a thoroughgoing numerical and experimental study where a successful agreement of the temporal evolution of the EF is found with the theoretical model.

Getting experimental insight into the EF resulting from guided IW is of high interest for the plasma community and beyond: towards large domains of applications. Indeed, the electron temperature is strongly related to the EF and plays a key role in the ionization mechanisms as well as the global kinetic of the plasma chemistry. Furthermore, the EF in guided IW is not uniform and is also time dependent which requires temporally and spatially resolved EF investigations also addressed as a future challenge in a recent review article [15].

In this paper, the authors report on an experimental study dealing with the characterization of the EF vector mapping of a guided IW in helium at atmospheric pressure. The work is centered around the simultaneous investigation of two orthogonal components of the EF space and time resolved. The aspects documented 
here are twofold.

- On the one hand, one focuses on the EF in the vicinity of the guided IW to prevent any perturbation induced by the measurement technique, and thus to study quantitatively the dynamic of the vector EF during the propagation.

- On the other hand, the EF properties of a guided IW in contact with a dielectric material will be presented to unveil the interaction between the plasma and a treated substrate.

\section{Experimental setup}

In this work, the guided IW are generated using a cold helium APPJ ambiguously named plasma gun [12] and not to be confused with running arcs or rail-gun in the literature [21, 22]. In outlines, the APPJ consists of a coaxial dielectric

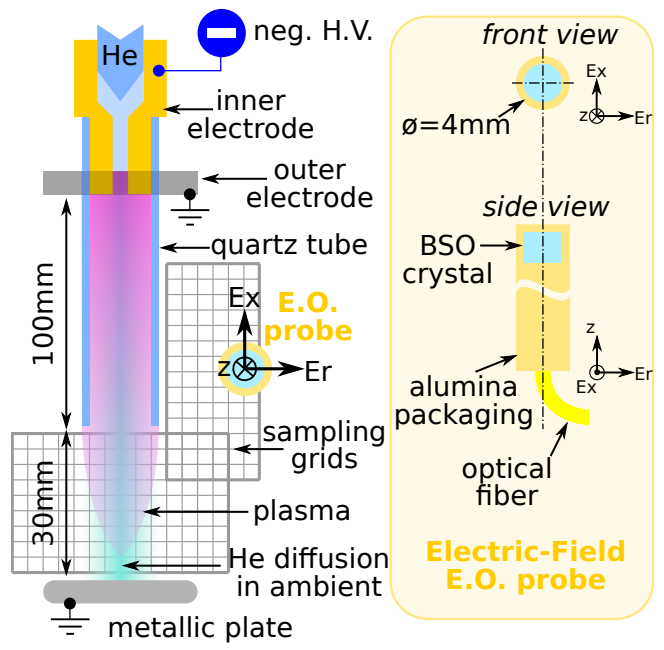

Figure 1. Schematic of the experimental setup. On the left hand side, the APPJ is depicted together with a conductive target and the measurement domains. On the right hand side, the E.O. probe used for the EF characterization is detailed with its two orthogonal axes of detection, $\overrightarrow{E_{x}}$ and $\overrightarrow{E_{r}}$.

barrier discharge design depicted in figure 1. A concentric assembly involves a pair of electrodes mounted on a $4.0 \mathrm{~mm}$ inner diameter quartz tube with $1.0 \mathrm{~mm}$ wall thickness. The powered electrode fits into the tube and allows one to inject helium through a $0.8 \mathrm{~mm}$ channel drilled along the axis. The grounded ring electrode is set on the outer surface of the tube and aligned with the tip of the powered electrode. The helium flow rate is set at $1.0 \mathrm{~L} / \mathrm{min}$ at standard conditions of temperature and pressure. The inner electrode is connected to a symmetric H.V. pulsed generator. In this work, repetitive negative pulses of $2.4 \mu \mathrm{s}$ FWHM and $1.3 \mu \mathrm{s}$ fall/rise time at the frequency of $1.0 \mathrm{kHz}$ are used exclusively. The H.V. negative waveform is measured on the electrode and plotted in figure 2. The choice of the negative polarity is twofold: from the emission of the light, the plasma seems homogeneous in volume and the gas flow pattern exiting the tube remains laminar in these conditions [19, 23]. This contributes to the stability of the rectilinear direction of the guided IW which propagates into the helium channel expanding in the ambient air. The partially ionized 
gas outside the quartz tube is the so-called plasma plume. Most of the geometries of APPJs cannot provide a fixed electric potential in the vicinity of the plasma plume which makes APPJs very sensitive to the electrical composition in its surrounding. Thus, the substrate of a treated sample is an important element of the electrical circuit of APPJs. Therefore, a conductive plate connected to the ground is placed $30 \mathrm{~mm}$ away from the tube outlet to fix a known electric potential in the vicinity of the plasma plume. It is important to mentioned that the guided IW - and thus the plasma plume - does not reach its surface, preventing a direct electric connection.

The EF diagnostic is carried out with a customized pigtailed electro-optic sensor (E.O.) commercialized by KAPTEOS S.A.s. and detailed in figure 1. This technology applied recently to plasmas [24] is based on the Pockels effect. The sensor is made of a cylindrical isotropic birefringent crystal probed with a laser beam guided through a fiber optic $[25,26]$. Depending on the variation of the light polarization induced by the external EF, the system is able to measure simultaneously the EF amplitude in two orthogonal directions of space. Although this method is not suitable for the measurement of static EF, the instrument is able to detect transient $\mathrm{EF}$ from tens of $\mathrm{kHz}$ up to $1 \mathrm{GHz}$ with a time resolution of $1 \mathrm{~ns}$ and a spatial resolution of the crystal size $(1.8 \mathrm{~mm} \times 2.0 \mathrm{~mm})$.

To perform a $2 \mathrm{D}$ characterization of the EF, the position in space the E.O. sensor is adjusted with a X-Y motorized translation stage. As shown in figure $1, \vec{E}_{x}$ axis of the E.O. sensor is parallel to the longitudinal axis of the APPJ while the orthogonal axis, $\vec{E}_{r}$, is collinear with the radius of the tube. Two sampling domains are defined and described as sampling grids in figure 1. One on the right side of the APPJ - along the tube - in order to characterize the EF of the guided IW without any disturbance from the probe. A second domain is located within the gap between the exit of the tube and the metallic plate, where the plasma plume expands. In the later condition, the E.O. probe is directly in contact with the plasma plume and acts as a dielectric treated substrate. In essence, the probe will also interact with the helium gas flow and modify its flow pattern. This will be discussed in the next section. In each node of the sampling grid, each signal waveform corresponding to the time evolution of the longitudinal $\left(\mathrm{E}_{\mathrm{x}}\right)$ and the radial $\left(\mathrm{E}_{\mathrm{r}}\right)$ response of the $\mathrm{EF}$ are recorded simultaneously with the oscilloscope. The antenna factors of both channels are also recorded simultaneously in order to scale the magnitude of each component of the $\mathrm{EF}[25]$. As the result, one defines the EF strength by,

$$
\|\vec{E}\|=\left(E_{x}^{2}+E_{r}^{2}\right)^{\frac{1}{2}} \text {. }
$$

The EF vector mapping is obtained after recording the signals from the probe in each node of the sampling grid after being triggered by the H.V. power supply. The waveforms recorded in each node are averaged over 512 shots with a $1 \mathrm{GHz}$ band-bass oscilloscope. In order to reconstruct the EF maps and sequences over the time, a Python script was developed to process the data. The outcome is the data processing is a 2D map resulting from an overlay of a quiver plot describing the direction of the EF vector and a contour plot with a color-map scaling the magnitude of the $\mathrm{EF}$ strength according to (1).

Last but not least, the alignment of the probe axis have been performed before the measurements. A clear evidence of a correct alignment is demonstrated in figure 4a) where the IW is still far away from the probe, confined within the glass tube. In this case, the EF lines configuration refers to a pin-to-plane geometry where -in good 
assumption- the EF distribution in the vicinity of the grounded plane is homogeneous and uniform [27]. Indeed, in figure 4a) the probe measured a uniform field -vertically oriented along the $\mathrm{E}_{\mathrm{x}}$ axis- and a homogeneous $\mathrm{EF}$ strength within the sampling domain. Thus, a misalignment of the probe axis -due to a rotation- would be clearly visible on the vector field distribution. Obviously, according to (1) the EF strength is not angular dependent.

\section{Results and discussion}

An example of the time evolution of both $\mathrm{E}_{\mathrm{x}}$ and $\mathrm{E}_{\mathrm{r}}$ is presented in figure 2. The

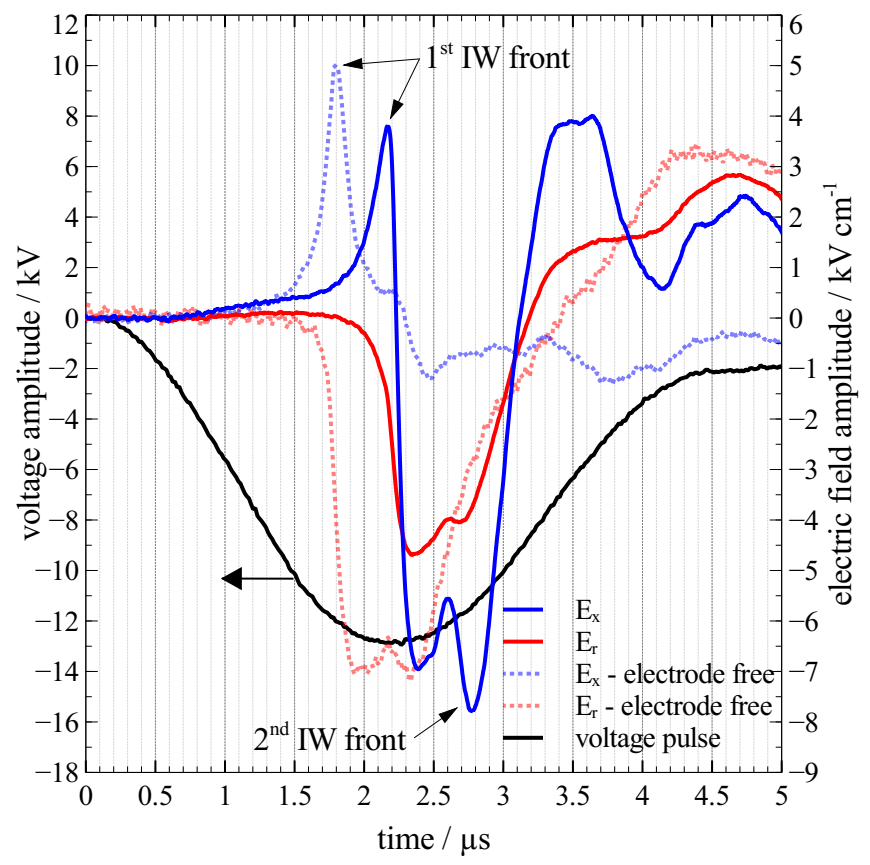

Figure 2. Time evolution of the voltage pulse, the axial $\left(\mathrm{E}_{\mathrm{x}}\right)$ and radial $\left(E_{r}\right)$ amplitude of the EF. The center of the E.O. probe is located at $5.2 \mathrm{~mm}$ from the APPJ axis. The term "electrode free" is used when the APPJ operates without any grounded ring electrode like in [20]. In the latter, the measurement is performed $50 \mathrm{~mm}$ from the tip of the inner electrode while in the case of continuous lines, the signals were acquired $25 \mathrm{~mm}$ further.

set of curves in continuous line are related to this study while the set drawn in dash line refers to prior investigations correlating successfully experimental and numerical simulations results [20]. Focusing first on $\mathrm{E}_{\mathrm{x}}$ signals, the front of the IW is clearly identified as a sharp peak of about $200 \mathrm{~ns}$ with an amplitude of several $\mathrm{kV} / \mathrm{cm}$ as already reported in $[19,20,23]$. A time delay between both signals is found around $360 \mathrm{~ns}$ due to the two different vertical positions of the measurement. The propagation velocity of the IW front is estimated around $7 \times 10^{6} \mathrm{~cm} / \mathrm{s}$ which is in agreement with prior studies [20]. Shortly after the IW front passed, one notices a quick fall of $\mathrm{E}_{\mathrm{r}}$ resembling a square pulse of $1 \mu \mathrm{s}$ FWHM with an amplitude between $4.5 \mathrm{kV} / \mathrm{cm}$ and $8 \mathrm{kV} / \mathrm{cm}$. The reason of this intense radial EF is explained by the creation of a - partially - conductive channel formed within the tube after the propagation of 
the IW front. Due to a significant density of charges and the direct contact of the plasma channel with the powered electrode, the square feature in the $\mathrm{E}_{\mathrm{r}}$ signals result from the dynamic of the H.V. pulse. The electric potential is thus transferred from the inner electrode to the plasma column from where results the intense radial EF. Depending on the electrical configuration of the APPJ, the dynamic of the voltage pulse can have a significant influence on $\mathrm{E}_{\mathrm{x}}$ [23]. Indeed, in case of an APPJ free of grounded ring electrode, one can observe a negative peak occurring at $2.4 \mu \mathrm{s}$ which corresponds exactly on time with the applied voltage imposed by the generator and rising to the ground potential. This negative peak of $\mathrm{E}_{\mathrm{x}}$ is drastically enhanced (down to $-7 \mathrm{kV} / \mathrm{cm}$ ) for an APPJ reactor equipped with a grounded electrode. Furthermore, on the same signal, a global minimum of $\mathrm{E}_{\mathrm{x}}$ is seen at $2.8 \mu$ s i.e. $0.6 \mu \mathrm{s}$ after the IW front. The latter results from the second IW front propagation as discussed in [28]. For matter of fact, the curves plotted on the graphs reported in [28] p.256-258 seem to be in agreement with the waveforms of $E_{x}$ and $E_{r}$ presented in figure 2.

Figure 3 presents a sequence of EF vector mapping sampled on the right hand side of the APPJ. The data shown in those maps are time dependent signals of $E_{\mathrm{x}}$ and $\mathrm{E}_{\mathrm{r}}$ - such as shown in figure 2 - recorded for different nodes of the sampling grid. By processing the data set, the vector field can be displayed, revealing the EF lines together with the EF strength. The direct visualization of the IW front is depicted in figure 3a) with a strong EF gradient and the vectors pointing toward the front. The direction of the EF results from the negative charge - mainly electron due to their higher mobility - ahead of the IW. At $2.2 \mu \mathrm{s}$, the H.V. pulse reaches its minimum at $-13 \mathrm{kV}$ imposed to the plasma channel. Figure $3 \mathrm{~b}$ ) shows the EF resulting from the negative charge attached to the inner surface of the tube balancing the positive space charge which bounds the plasma column [29]. This is sustained as long as the level of the applied voltage is not back to the ground potential. Thus an intense EF from the plasma column extends up to $-40 \mathrm{~mm}$ and giving rise to a negative (anode-directed) guided streamer [27]. The propagation of the IW starts to slow down around $2.4 \mu \mathrm{s}$, i.e when the electric potential is at the minimum. Then, the latter begins to increase relatively to the plasma channel potential, leading to a fast increase of the electric potential of the inner electrode which stops the propagation of the first IW as shown in figure 3c). The EF strength drops quickly as well as the electron kinetics which will affect the plasma properties, for instance He metastable densities [28]. The localized intense $\mathrm{EF}$ at $-45 \mathrm{~mm}$ corresponds to the tube outlet and indicates a significant attachment of transient charge distributed around the tube section. Intuitively, the magnitude of the induced EF is dependent on the shaping of the tube edge and the density of charge. On figure 3d), one notices an enhancement of the transient charge deposition and the resulting EF measured over several tens of ns. The direction of the $\mathrm{EF}$ indicates the presence of negative charge. Back diffusion of ambient air into the He gas flow was already observed, particularly with the emission of excited atomic oxygen [30,31]. According to [29], $\mathrm{O}_{2}{ }^{-}$are the dominant negative ions at the exit of the tube due to a smaller $\mathrm{T}_{\mathrm{e}}$ being favorable to electrons to attach to $\mathrm{O}_{2}$. Although the technique involved in this study cannot provide any information about static charge, deposited charges have been recently investigated [32, 33]. In [33], the authors estimated the loss within the tube around $0.1 \mathrm{nC} / \mathrm{cm}^{2}$.

The rapid increase of the electrode potential induces a second IW front propagating with a strong EF polarized in the opposite direction with the first IW. The separation between both IW is characterized by a sharp gradient of EF creating a gap where the value of the EF strength is damped close to $0 \mathrm{kV} / \mathrm{cm}$. At $2.75 \mu \mathrm{s}$, the applied 


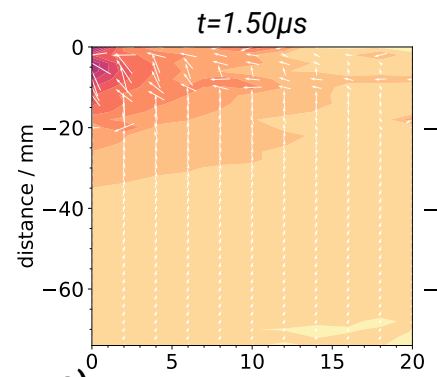

a)
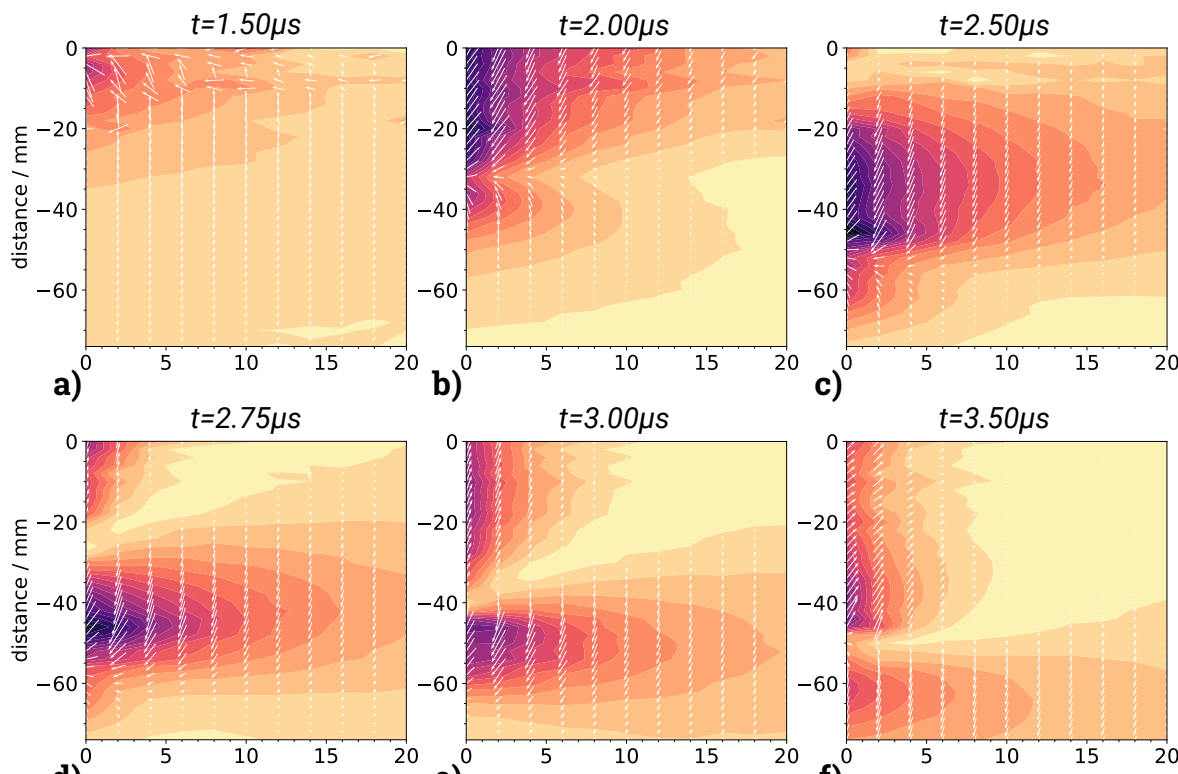

b)
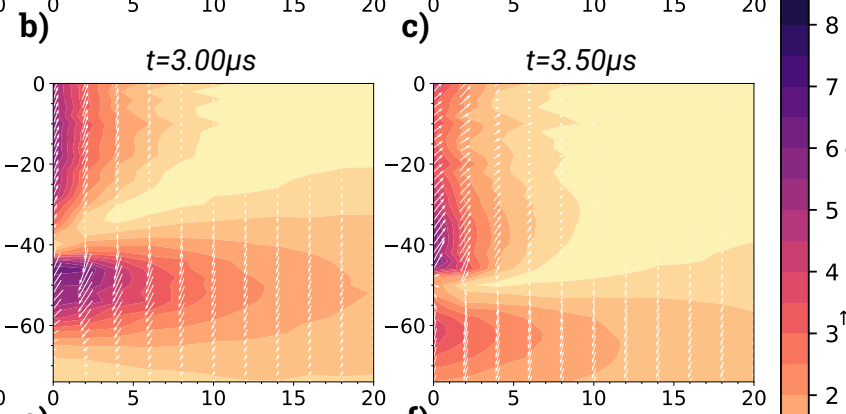

d)

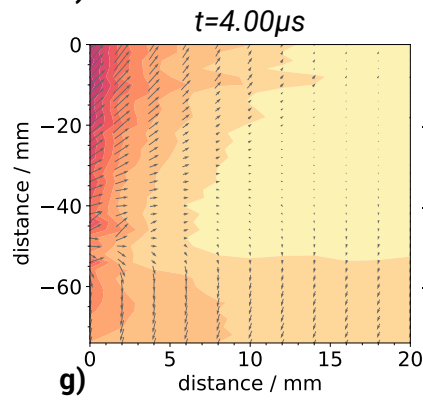

e)
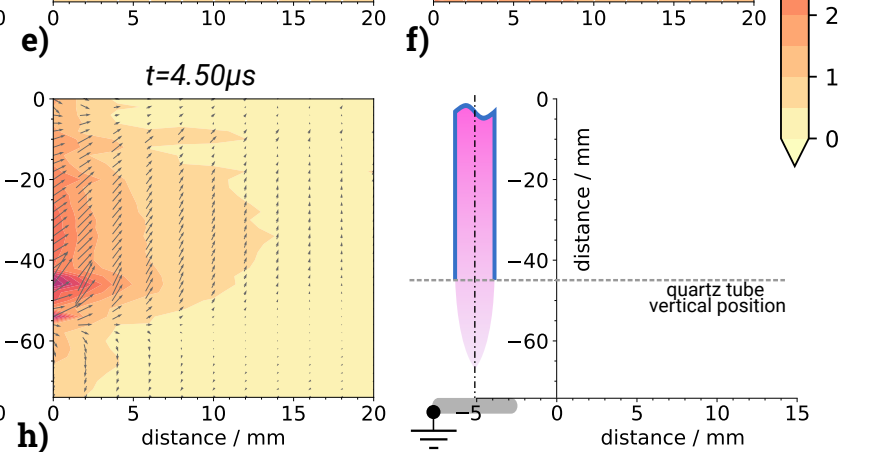

Figure 3. Sequence of EF vector mapping on the right hand side of the propagation of the guided IW from the APPJ. On the vertical axis, the origin is located $55 \mathrm{~mm}$ from the tip of the inner electrode so that $-75 \mathrm{~mm}$ corresponds to the surface of the grounded metallic plate (see figure 1). Thus, the tip of the quartz tube is at $-45 \mathrm{~mm}$. The guided IW propagation being from top to bottom, the distance values are negative by convention. On the horizontal axis, the origin - being the closest to the tube - corresponds to the center of the E.O. probe crystal positioned $5.2 \mathrm{~mm}$ from the APPJ axis.

potential imposed by the generator is distributed along the conductive channel after the propagation of the second IW. Consequently, the EF direction reverses due to an electrode potential being increased compared to the charge residual of the first IW and the charging of the wall tube by positive charge [34]. This brutal flipping of the EF influences the ionization dynamic and the electron kinetic which govern the whole plasma chemistry kinetic. The propagation of the second IW within the tube is shown in figure 3e). The contribution of the negative charge at the tube exit to weaken significantly the EF of the second IW is clearly identified. As the result, the shaping of the tube exit must play a key role in the dynamic of the IW propagation and the plasma dynamics due to the presence of a local $\mathrm{EF}$ of tens of $\mathrm{kV} / \mathrm{cm}$. The plasma column is sustained until the applied voltage returns back to the ground po- 
tential. The quick rise of the electrode potential compared with the potential of the ionized channel induces the propagation of the second IW leading to the formation of a positive (cathode-directed) guided streamer-like [27]. Indeed, the direction of the $\mathrm{EF}$ vectors of the plasma channel indicates a positive charging of the tube wall and confirms prior predictive numerical work regarding positive guided streamer mechanism [34]. Last but not least, the EF strength is measured to be higher in the column of the negative streamer compared to the positive streamer which is in agreement with several predictive models $[35,36]$.

APPJs are also driven with AC H.V. power supply where the existence of a second IW front may be questioned. According to [37], with slow AC regime, a IW is ignited at each half-period. Further investigations are necessary to identify the role of the frequency and the H.V. amplitude for the generation of a second guided IW.

The second part of this study focuses on the vector nature of the EF in the plasma plume region. In this case, the dielectric probe will interact and modify the helium flow pattern which is analogous to some process conditions where the APPJ is applied to treat dielectric surfaces. In contrast with the previous experiment, the E.O. probe is now being directly in contact with the IW during scanning operations. Sequences of EF vectors maps are presented in figure 4. Depending on the position of the E.O. probe, the plasma plume can impinge on the alumina surface protecting the BSO crystal. In this case, it is important to clarify that the interpretation of the results differs from the previous set. Indeed, the EF strength values shown in figure 4 are not within the IW front, but correspond to the EF intensity under a dielectric surface - of a relative permittivity $\left(\varepsilon_{r}=\varepsilon / \varepsilon_{0}\right), \varepsilon \approx 10$ - touching the plasma plume. However, the directions of the EF vectors are assumed to do not be affected by the surface. In figure $4 \mathrm{a}$ ), the EF vectors is polarized vertically, directed toward the negative charge ahead of the IW front which is propagating into the tube. At $1.94 \mathrm{\mu s}$, the IW front has already exited the tube and propagates into the ambient. An intense EF expands within a symmetric volume of $30 \mathrm{~mm}$ large and a maximum strength up to $50 \mathrm{kV} / \mathrm{cm}$. Such extreme EF measured under the $1.0 \mathrm{~mm}$ dielectric layer results from the interaction of the plasma with the surface. In the present case, the relatively low $\varepsilon_{r}$, the continuity of the electric displacement vector, $\vec{D}=\varepsilon \vec{E}$ allows for an effective penetration of the longitudinal EF of the IW front through the surface. The EF strength is enhanced due to the transient charge deposited on top of the surface. A recent numerical work on plasma jet interacting with various dielectric and metal surfaces documents EF strength value in good agreement with the present experiment [29]. The computed value under the surface of $\varepsilon_{r}=10$ ranges from $14 \mathrm{kV} / \mathrm{cm}$ to $40 \mathrm{kV} / \mathrm{cm}$. Although in the current study, it is not possible to untangle the contribution of the IW front and the transient charge to the EF strength, the maximum value is reached around $2.30 \mu \mathrm{s}$, when the first IW front exits the tube. In figure 4c) and d), the applied voltage pulse has passed its minimum amplitude to start the rising slope which leads to a separation of the first IW as previously mentioned. Interestingly, the EF direction in the vicinity of the tube exit describes a curl which is attributed to the presence of negative charge, such as $\mathrm{O}_{2}{ }^{-}$at the tip of the glass tube [29].

The steep increase of the applied voltage imposed to the plasma channel implies a flip of the EF and the creation of a second IW shown in figure 4e). At this time (2.4 $\mu \mathrm{s})$, an isolated EF source up to $25 \mathrm{kV} / \mathrm{cm}$ is observed at $-15 \mathrm{~mm}$ being generated by negative charge stored on the dielectric surface. The recombination of the charges leads to a significant decrease of the EF strength while the second IW propagates. The dynamic of both processes gives rise to an intriguing configuration of the EF lines as shown 

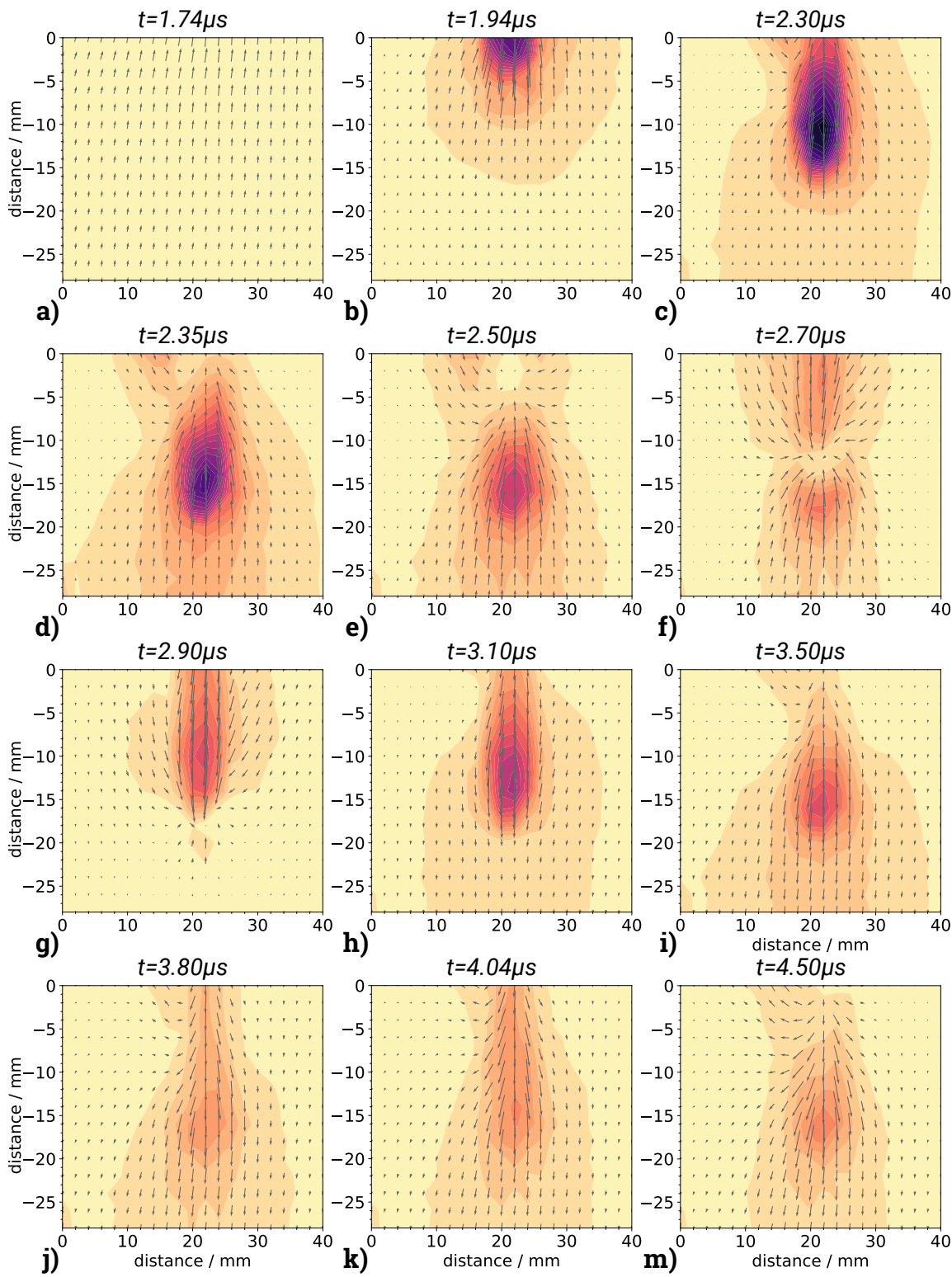

Figure 4. Sequence of EF vector mapping at the APPJ exit. On the vertical axis, the origin corresponds to the tube end i.e. $100 \mathrm{~mm}$ from the inner electrode. The position of the surface of the grounded metallic plate is at $-30 \mathrm{~mm}$ (see figure 1). The guided IW propagation being from top to bottom, the distance values are negative by convention. On the horizontal axis, the axis of the APPJ tube is at $22 \mathrm{~mm}$.

in figure 4f). The map reveals a head-to-tail EF configuration separated by a gap at $-12 \mathrm{~mm}$ where the EF induced by the second IW and the surface charge compensate each other. It is anticipated that such EF feature must have a significant influence on the ionization mechanism and chemical kinetic of the plasma. The recombination of the charge on top of the surface by the second IW allows the latter to propagate fur- 
ther. At $2.9 \mathrm{\mu s}$, the EF is polarized vertically, flipped upside down, revealing the path of the ionized channel produced by the IW propagation. The structure of the EF and the magnitude up to $30 \mathrm{kV} / \mathrm{cm}$ evidences the existence of a second IW propagating in to the mixture of helium and air. The charging of the surface significantly contributes to the EF strength after the applied voltage returned back to the ground potential. Knowing the key role of the EF the production mechanism of reactive species, it is assumed that the whole plasma chemistry must be strongly affected in case of liquid substrate in contact with IW.

\section{Concluding remarks}

Focusing on the essence of APPJs - guided IWs-, this manuscript reports for the first time on experimental EF vector characterization. Measurements performed with a unique technology based on E.O. probe allow us to produce EF vector mapping of guided IWs. Propagation velocities of the IW are in agreement with prior works based on the investigation of light emission. It is shown that APPJs powered with a us H.V. pulse generator initiate the propagation of two consecutive guided IW with opposite EF vector direction. It is discussed that the time scale of the H.V. pulse and the remaining ionization of the channel created by the first guided IW are crucial parameters for the generation of a second guided IW. The transient EF due to the attachment of charge on the wall has been identified and a specific attention must be paid to the shaping of the section of the tube.

$\mathrm{EF}$ vector mapping measured under a dielectric surface in contact with the IW brings new insights into the EF lines complexity driving the electron kinetic and therefore the global non-equilibrium chemistry. A maximum of $55 \mathrm{kV} / \mathrm{cm}$ is measured under the dielectric surface. The dynamic of the first IW is consistent non-intrusive measurements although the presence of a dielectric substrate in contact with the IW implies a change of the electric properties. The evidence of a second guided IW is documented and unveils an intriguing head-to-tail configuration of the EF vector direction. This preliminary study opens new ways to investigate experimentally EF induced by guided IWs and derived plasma devices such as APPJs. A plethora of applications will benefit from EF vector characterization to understand and to optimize plasma sources and processes, particularly in the field of plasma liquid interaction, surface modification, plasma medicine and agriculture including plasma cell interactions.

\section{Acknowledgment}

The author would like to thank Kapteos collaborators for the helpful discussions concerning the use of the EO probe for vectorial and real time analysis of the electric field. Thanks to X. Damany for the fruitful discussions on this topic. S. Dozias is acknowledged for the electronic engineering and technical support.

Data and graphs have been exclusively processed with open-source libraries SciPy, NumPy [38], Veusz and Matplotlib [39]. 
Iseni 2020, IOP Plasma Res. Express, doi:10.1088/2516-1067/ab9b69

\section{References}

[1] von Woedtke T, Reuter S, Masur K and Weltmann K D 2013 Physics Reports 530 291-320 URL http://dx.doi.org/10.1016/j.physrep.2013.05.005

[2] Graves D B 2014 Physics of Plasmas 21080901 URL http://dx.doi.org/10.1063/1.4892534

[3] Foster J, Sommers B S, Gucker S N, Blankson I M and Adamovsky G 2012 IEEE Transactions on Plasma Science 40 1311-1323 URL http://dx.doi.org/10.1109/tps.2011.2180028

[4] Bruggeman P J, Kushner M J, Locke B R, Gardeniers J G E, Graham W G, Graves D B, Hofman-Caris R C H M, Maric D, Reid J P, Ceriani E, Rivas D F, Foster J E, Garrick S C, Gorbanev Y, Hamaguchi S, Iza F, Jablonowski H, Klimova E, Kolb J, Krcma F, Lukes P, Machala Z, Marinov I, Mariotti D, Thagard S M, Minakata D, Neyts E C, Pawlat J, Petrovic Z L, Pflieger R, Reuter S, Schram D C, Schrter S, Shiraiwa M, Tarabová B, Tsai P A, Verlet J R R, von Woedtke T, Wilson K R, Yasui K and Zvereva G 2016 Plasma Sources Science and Technology 25053002 URL http://dx.doi.org/10.1088/0963-0252/25/5/053002

[5] Kim K N, Lee S M, Mishra A and Yeom G Y 2016 Thin Solid Films 598 315-334 URL http://dx.doi.org/10.1016/j.tsf.2015.05.035

[6] Penkov O V, Khadem M, Lim W S and Kim D E 2015 Journal of Coatings Technology and Research 12 225-235 URL http://dx.doi.org/10.1007/s11998-014-9638-z

[7] Moreau E 2007 Journal of Physics D: Applied Physics 40 605-636 URL http://dx.doi.org/10. 1088/0022-3727/40/3/s01

[8] Graves D B 2012 Journal of Physics D: Applied Physics 45263001 URL http://dx.doi.org/10. 1088/0022-3727/45/26/263001

[9] Fridman A 2008 Plasma Chemistry (Cambridge University Press) ISBN 9780511546075

[10] Lu X, Laroussi M and Puech V 2012 Plasma Sources Science and Technology 21034005 URL http://dx.doi.org/10.1088/0963-0252/21/3/034005

[11] Winter J, Brandenburg R and Weltmann K D 2015 Plasma Sources Science and Technology 24 064001 URL http://dx.doi.org/10.1088/0963-0252/24/6/064001

[12] Robert E, Sarron V, Riès D, Dozias S, Vandamme M and Pouvesle J M 2012 Plasma Sources Science and Technology 21034017 URL http://dx.doi.org/10.1088/0963-0252/21/3/034017

[13] Boeuf J P, Yang L L and Pitchford L C 2013 Journal of Physics D: Applied Physics 46015201 URL http://dx.doi.org/10.1088/0022-3727/46/1/015201

[14] Hofmann S, Sobota A and Bruggeman P 2012 IEEE Transactions on Plasma Science 402888 2899 URL http://dx.doi.org/10.1109/TPS.2012.2211621

[15] Lu X, Naidis G, Laroussi M and Ostrikov K 2014 Physics Reports 540 123-166 URL http: //dx.doi.org/10.1016/j.physrep.2014.02.006

[16] Teschke M, Kedzierski J, Finantu-Dinu E, Korzec D and Engemann J 2005 IEEE Transactions on Plasma Science 33 310-311 URL http://dx.doi.org/10.1109/tps.2005.845377

[17] Sretenović G B, Krstić I B, Kovačević V V, Obradović B M and Kuraica M M 2011 Applied Physics Letters 99161502 URL http://dx.doi.org/10.1109/tps.2012.2219077

[18] Naidis G V 2010 Journal of Physics D: Applied Physics 43402001 URL http://dx.doi.org/10. 1063/1.3576940

[19] Robert E, Darny T, Dozias S, Iseni S and Pouvesle J M 2015 Physics of Plasmas 22122007 URL http://dx.doi.org/10.1063/1.4934655

[20] Bourdon A, Darny T, Pechereau F, Pouvesle J M, Viegas P, Iséni S and Robert E 2016 Plasma Sources Science and Technology 25035002 URL http://dx.doi.org/10.1088/0963-0252/25/ $3 / 035002$

[21] Thom K, Norwood J and Jalufka N 1964 The Physics of Fluids 7 S67-S70 ISSN 0031-9171

[22] Lisnyak M 2018 Theoretical, numerical and experimental study of DC and AC electric arcs phdthesis Université d'Orléans, France URL https://tel.archives-ouvertes.fr/tel-01808258

[23] Darny T 2016 Étude de la production des espèces réactives de l'oxygène et de l'azote par décharge Plasma Gun à pression atmosphérique pour des applications biomédicales phdthesis Université d'Orléans, France URL https://tel.archives-ouvertes.fr/tel-01661500

[24] Gaborit G, Reuter S, Iseni S and Duvillaret L 2014 Cold Plasma Diagnostic Using Vectorial Electrooptic Probe $5^{\text {th }}$ International Conference on Plasma Medicine (ICPM5) (Nara, Japan) URL http://dx.doi.org/10.13140/RG.2.2.12378.13768

[25] Gaborit G, Jarrige P, Lecoche F, Dahdah J, Duraz E, Volat C and Duvillaret L 2014 IEEE Transactions on Plasma Science 42 1265-1273 URL http://dx.doi.org/10.1109/tps.2014. 2301023

[26] Gaborit G, Artillan P, Bermond C, Revillod G, Chevrier-Gros G and Duvillaret L 2020 IEEE Antennas and Wireless Propagation Letters 1-1 URL https://doi.org/10.1109/LAWP.2020. 2994263 
[27] Raizer Y P 1991 Gas Discharge Physics (Springer-Verlag Berlin Heidelberg) ISBN 364264760X

[28] Darny T, Pouvesle J M, Puech V, Douat C, Dozias S and Robert E 2017 Plasma Sources Science and Technology 26045008 URL http://dx.doi.org/10.1088/1361-6595/aa5b15

[29] Norberg S A, Johnsen E and Kushner M J 2015 Journal of Applied Physics 118013301 URL http://dx.doi.org/10.1063/1.4923345

[30] Iséni S, Damany X, Sretenović G, Kovačević V, Krstić I, Dozias S, Pouvesle J M, Kuraica M and Robert E 2016 Electric field and discharge properties of single and multiple arrangement of pulsed atmospheric plasma streams $28^{\text {th }}$ Summer School and International Symposium on the Plysics of Ionized Gases (SPIG2016) (Belgrade, Serbia) ISBN 978-86-84539-14-6

[31] Iséni S, Damany X, Darny T, Douat C, Dozias S, Pouvesle J M and Robert E 2016 Electric field characterization of plasma gun and multi-jet plasma arrays $6^{\text {th }}$ International Conference on Plasma Medicine (ICPM6) (Bratislava, Slovakia)

[32] Wild R, Gerling T, Bussiahn R, Weltmann K D and Stollenwerk L 2013 Journal of Physics D: Applied Physics 47042001 URL http://dx.doi.org/10.1088/0022-3727/47/4/042001

[33] Slikboer E, Garcia-Caurel E, Guaitella O and Sobota A 2017 Plasma Sources Science and Technology 26035002 URL http://dx.doi.org/10.1088/1361-6595/aa53fe

[34] Xiong Z and Kushner M J 2012 Plasma Sources Science and Technology 21034001 URL http://dx.doi.org/10.1088/0963-0252/21/3/034001

[35] Naidis G V 2011 Applied Physics Letters 98141501 URL http://dx.doi.org/10.1063/1.3576940

[36] Xiong Z, Robert E, Sarron V, Pouvesle J M and Kushner M J 2013 Journal of Physics D: Applied Physics 46155203 URL http://dx.doi.org/10.1088/0022-3727/46/15/155203

[37] Sretenović G B, Krstić I B, Kovačević V V, Obradović B M and Kuraica M M 2014 Journal of Physics D: Applied Physics 47102001 URL http://dx.doi.org/10.1088/0022-3727/47/10/ 102001

[38] van der Walt S, Colbert S C and Varoquaux G 2011 Computing in Science Es Engineering 13 22-30 URL http://dx.doi.org/10.1109/mcse.2011.37

[39] Hunter J D 2007 Computing in Science 63 Engineering 9 90-95 URL http://dx.doi.org/10.1109/ mcse. 2007.55 